АНАЛИЗ НОРМАТИВНО-ПРАВОВЫХ АКТОВ ПО ОРГАНИЗАЦИИ ЛЕКАРСТВЕННОГО ОБЕСПЕЧЕНИЯ ОТДЕЛЬНЫХ КАТЕГОРИЙ ГРАЖДАН, ИМЕЮЩИХ ПРАВО НА МЕРЫ СОЦИАЛЬНОЙ ПОДДЕРЖКИ

(с) О.А. Нагибин, О.Н. Селявина, Л.Е. Караушева

Рязанский государственный медицинский университет имени академика И.П. Павлова, Рязань, Российская Федерация

Для урегулирования лекарственного обеспечения льготных категорий граждан создана законодательная база, которая определяет отдельные группы населения и категории заболеваний, а также перечни лекарственных препаратов для льготного лекарственного обеспечения. В настоящий момент существует разделение лекарственного обеспечения на федеральный и региональный уровни. В статье представлен анализ законодательной базы, который выявил, что с одной стороны, существует система по распределению бюджетных средств в соответствии с установленными категориями граждан и действующими ограничительными перечнями лекарственных препаратов, с другой стороны - имеются не до конца разрешенные противоречия и дублирования в законодательных актах, что негативно сказывается на организации здравоохранения в нашей стране. Однако, нормативная база изменяется, обновляясь с утверждением новых программ государственных гарантий, федеральных перечней лекарственных препаратов и прочих нормативных документов. Таким образом, имеются дальнейшие перспективы по обновлению законодательных актов, которые были утверждены достаточно давно и требуют гармонизации с действующей на сегодняшней день нормативно-правовой базой. На региональном уровне существуют до конца нерешенные законодательные и практические трудности. Для их решения необходима доработка существующих нормативно-правовых актов или разработка новой законодательной базы. При этом оба пути представляют собой сложную задачу, от решения которой зависят жизнь и здоровье отечественных пациентов.

Ключевые слова: льготное лекарственное обеспечение; льготные категории граждан; Постановление Правительства 890; Программа государственных гарантии; перечень ЖНВЛП; ОНЛП; высоко-затратные нозологии; орфанные болезни; врачебная комиссия.

\title{
ANALYSIS OF REGULATORY LEGAL ACTS ON ORGANIZATION OF PHARMACEUTICAL PROVISION OF CERTAIN CATEGORIES OF CITIZENS WITH THE RIGHT TO SOCIAL SUPPORT
}

\author{
O.A. Nagibin, O.N. Selyavina, L.E. Karausheva
}

Ryazan State Medical University, Ryazan, Russian Federation

To regulate the pharmaceutical provision of privileged categories of citizens, a legislative framework has been created that determines certain groups of the population and categories of diseases, as well as lists of drugs for preferential drug provision. Currently, there is a separation of drug provision to the federal and regional levels. The article presents an analysis of the legislative 
framework, which showed that, on the one hand, there is a system for distribution of budget funds in accordance with the established categories of citizens and the current restrictive lists of drugs, on the other hand, there are incompletely resolved contradictions and duplications in legislative acts, which negatively affects the organization of health care in our country. However, regulatory framework constantly changes and renews through approval of new programs of state guarantees, federal lists of medical drugs and other normative documents. Thus, there exist further prospects for refreshment of legislative acts that were approved a long time ago and require harmonization with the current normative-legal framework. There exist legislative and practical problems that still remain unsolved. To solve them, it is necessary to finalize the existing regulatory legal acts or develop a new legislative framework. With this, both ways are a difficult task, on solution of which the life and health of patients depend.

Keywords: pharmaceutical provision; benefit-entitled categories; Government Decree 890; state guarantee; list of VED; PNMP; cost-intensive nosologies; orphan diseases; health authorities (medical commission.

Для урегулирования лекарственного обеспечения льготных категорий граждан создана законодательная база, которая определяет отдельные группы населения и категории заболеваний, а также перечни лекарственных препаратов для льготного лекарственного обеспечения. В настоящий момент существует разделение лекарственного обеспечения на федеральный и региональный уровни. Однако часть полномочий и прав дублируются на обоих уровнях, что негативно отражается на расходовании бюджетных средств и создает организационные проблемы. Анализ существующей законодательной базы позволит определить направления для дальнейшего усовершенствования нормативно-правовых актов по льготному лекарственному обеспечению.

В Федеральном Законе от 21.11.2011 № 323 «Об основах охраны здоровья граждан в Российской Федерации» (далее - Ф3 «Об основах охраны здоровья») разделены полномочия органов государственной власти субъектов Российской Федерации в сфере охраны здоровья. Как следует из части 2 статьи 81:

«2. В рамках территориальной программы государственных гарантий бесплатного оказания гражданам медицинской помощи органы государственной власти субъектов Российской Федерации устанавливают:

5) перечень лекарственных препаратов, отпускаемых населению в соответ- ствии с Перечнем групп населения и категорий заболеваний, при амбулаторном лечении которых лекарственные средства и изделия медицинского назначения отпускаются по рецептам врачей бесплатно, а также в соответствии с Перечнем групп населения, при амбулаторном лечении которых лекарственные средства отпускаются по рецептам врачей с пятидесятипроцентной скидкой...» [1].

Группы населения, определенные в пятом подпункте части 2 статьи 81 Федерального закона, относятся к региональным льготным категориям граждан или «региональным льготникам». При этом в данном подпункте не указывается, что «Перечень групп населения и категорий заболеваний» (региональных льготников) утверждается Правительством РФ [1]. В отличие от этого, в федеральных законодательных актах установлены полномочия Правительства РФ по формированию перечней лекарственных препаратов в тех случаях, когда обеспечение препаратами из этих перечней отнесено к полномочиям федеральных органов государственной власти.

Нормативно-правовые акты, регулирующие лекарственное обеспечение на федеральном уровне

В Федеральном законе от 17.07.99 №178 «О государственной социальной помощи» установлены меры социальной поддержки в виде предоставления до- 
полнительной бесплатной медицинской помощи, предусматривающей обеспечение необходимыми лекарственными препаратами по рецептам врача отдельных категорий граждан за счет средств федерального бюджета (программа ОНЛП). Указанные отдельные категории граждан относятся к так называемым «федеральным льготникам» [2].

На основании статьи 6.1. данного закона «Перечень лекарственных средств, в том числе перечень лекарственных средств, назначаемых по решению врачебных комиссий лечебно-профилактических учреждений... утверждаются федеральным органом исполнительной власти, осуществляющим выработку государственной политики и нормативное правовое регулирование в сфере здравоохранения и социального развития». Перечень лекарственных препаратов для «федеральных льготников» утверждается Правительством РФ. С 1 января 2019 года вступил в силу новый перечень, утвержденный Распоряжением Правительства РФ от 10.12.2018 №2738-p [3].

Средства на финансовое обеспечение мер социальной поддержки федеральных льготных категорий граждан, которые проживают в регионах, перечисляются из федерального бюджета в региональный в виде межбюджетных трансфертов и субвенций при помощи расчета потребности, выполненного на основании количества граждан, сохранивших право на набор социальных услуг в части лекарственного обеспечения. Таким образом, перечень льготных категорий граждан, перечень лекарственных препаратов для обеспечения «федеральных льготников» проходят утверждение на федеральном уровне. Финансирование льготного лекарственного обеспечения указанных категорий граждан осуществляется за счет средств Федерального бюджета.

Также следует отметить, что по представленной схеме на федеральном уровне утверждается также «Программа высокозатратных нозологий». История создания данной программы берет свое начало с Приказа МЗ СР РФ от 9 марта 2007 года
№159 «О мерах по обеспечению отдельных категорий граждан необходимыми лекарственными средствами». Согласно указанному нормативному документу, наиболее затратные с точки зрения лекарственного обеспечения заболевания (7 нозологий), исключаются из программы ОНЛП и переводятся на непосредственное финансирование из федерального бюджета РФ. Как следствие, из ОНЛП были исключены и дорогостоящие препараты для терапии 7 высокозатратных нозологий [4].

Согласно Приказу МЗ СР РФ от 9 марта 2007 года №159: «наиболее затратными заболеваниями являлись гемофилия, муковисцидоз, гипофизарный нанизм, болезнь Гоше, некоторые злокачественные новообразования лимфоидной, кроветворной и родственных им тканей, рассеянный склероз, лица после трансплантации органов и (или) тканей». Как было отмечено выше, лекарственное обеспечение для пациентов, страдающих данными заболеваниями, осуществляется из средств федерального бюджета.

С 1 января вступил в силу Федеральный закон от 3 августа 2018 года №299-Ф3 «О внесении изменений в Федеральный закон «Об основах охраны здоровья граждан в Российской Федерации», принятый Государственной Думой 26 июля 2018 года и одобренный Советом Федераций 28 июля 2018 года, согласно которому перечень высокозатратных заболеваний был дополнен такими нозологиями, как гемолитико-уремический синдром, юношеский артрит с системным началом, мукополисахаридоз I, II, VI типов.

В связи с расширением с 2019 года программы высокозатратных технологий были изменены правила организации обеспечения лекарствами лиц, больных 12 редкими заболеваниями и правила ведения федерального регистра указанных лиц.

Лекарства для больных с перечисленными диагнозами закупает Минздрав России за счет средств федерального бюджета. В работе медучреждений и аптек принципиальных изменений нет. Им по-прежнему нужно передавать сведения о необходимом количестве лекарств в региональные 
управления здравоохранением. А последние уже на основании этих данных составят заявки на поставку препаратов и направят их в Минздрав. Таким образом, закупка препаратов для лекарственного обеспечения больных высоко-затратными нозологиями производятся централизованно Министерством здравоохранения Российской Федерации с последующим распределением по регионам на основании утвержденной заявки.

Одно из нововведений касается также того, что больные могут обращаться в медорганизации по месту пребывания, а не только по месту жительства. Это возможно, если срок пребывания превышает шесть месяцев.

Финансирование лекарственного обеспечения для данной категории льготников определено Программой государственных гарантий (ПГГ) бесплатного оказания гражданам медицинской помощи. 10 декабря 2018 года Правительством Российской Федерации была утверждена Программа государственных гарантий бесплатного оказания гражданам медицинской помощи на 2019 год и на плановый период 2020 и 2021 года (утв. Постановлением Правительства РФ № 1506), которая утверждает следующее:

«За счет бюджетных ассигнований федерального бюджета осуществляется финансовое обеспечение: закупки лекарственных препаратов, предназначенных для лечения лиц, больных гемофилией, муковисцидозом, гипофизарным нанизмом, болезнью Гоше, злокачественными новообразованиями лимфоидной, кроветворной и родственных им тканей, рассеянным склерозом, гемолитико-уремическим синдромом, юношеским артритом с системным началом, мукополисахаридозом I, II и VI типов, лиц после трансплантации органов и (или) тканей по перечню лекарственных препаратов, сформированному в установленном порядке и утверждаемому Правительством Российской Федерации...».

Таким образом, на федеральном уровне утверждается как перечень высокозатратных нозологий, так и перечень лекарственных препаратов для лечения этих заболеваний; в свою очередь, финансирование этого лекарственного обеспечения происходит из средств федерального бюджета.

Как видно из представленных примеров, лекарственное обеспечение на основании перечней лекарственных препаратов, утверждаемых на федеральном уровне, осуществляется за счет финансовых потоков, следующих из федерального бюджета РФ. Напротив, в случае с лекарственным обеспечением льготных категорий граждан на региональном уровне, в основе лежит другая законодательная база с отличными принципами.

\section{Нормативно-правовые акты, регу- лирующие лекарственное обеспечение на региональном уровне}

Согласно Ф3 «Об основах охраны здоровья» установлены полномочия органов государственной власти субъектов Российской Федерации в сфере охраны здоровья. Так, в части 1 статьи 16 сказано:

«1. К полномочиям органов государственной власти субъектов Российской Федерации в сфере охраны здоровья относятся:

...3) разработка, утверждение и реализация территориальной программы государственных гарантий бесплатного оказания гражданам медицинской помощи, включающей в себя территориальную программу обязательного медицинского страхования...»

В этом же Федеральном законе в статье 81 сказано о перечнях лекарственных препаратов и групп населения:

«2. В рамках территориальной программы государственных гарантий бесплатного оказания гражданам медицинской помощи органы государственной власти субъектов Российской Федерации устанавливают:

5) перечень лекарственных препаратов, отпускаемых населению в соответствии с Перечнем групп населения и категорий заболеваний, при амбулаторном лечении которых лекарственные средства и изделия медицинского назначения отпускаются по рецептам врачей бесплатно, а также в соответствии с Перечнем групп населения, при амбулаторном лечении 
которых лекарственные средства отпускаются по рецептам врачей с пятидесятипроцентной скидкой...».

В подпункте 5 ч. 2 статьи 81 Ф3 «Об основах охраны здоровья» нет указания на то, что «Перечень групп населения и категорий заболеваний» (региональных льготников) утверждается Правительством РФ. Также нет и нормы по утверждению Правительством РФ перечня лекарственных препаратов для этих целей [1].

Программа государственных гарантий бесплатного оказания гражданам медицинской помощи на 2019 год и на плановый период 2020 и 2021 года (утвержденная Постановлением Правительства РФ 10 декабря 2018 года №1506) в разделе V «Финансовое обеспечение Программы» устанавливает следующее:

«За счет бюджетных ассигнований бюджетов субъектов Российской Федерации осуществляется:

...обеспечение лекарственными препаратами в соответствии с перечнем групп населения и категорий заболеваний, при амбулаторном лечении которых лекарственные препараты и медицинские изделия в соответствии с законодательством Российской Федерации отпускаются по рецептам врачей бесплатно; обеспечение лекарственными препаратами в соответствии с перечнем групп населения, при амбулаторном лечении которых лекарственные препараты отпускаются по рецептам врачей с 50-процентной скидкой...» [5].

Требования к территориальной программе по определению перечня лекарственных препаратов, отпускаемых населению в соответствии с перечнем групп населения и категорий заболеваний, отражены в разделе VIII ПГГ «Требования к территориальной программе в части определения порядка, условий предоставления медицинской помощи, критериев доступности и качества медицинской помощи» определяет следующее:

«Территориальная программа в части определения порядка и условий оказания медицинской помощи должна включать: ...перечень лекарственных препаратов, отпускаемых населению в соответствии с перечнем групп населения и категорий заболеваний, при амбулаторном лечении которых лекарственные средства и изделия медицинского назначения отпускаются по рецептам врачей бесплатно, а также в соответствии с перечнем групп населения, при амбулаторном лечении которых лекарственные средства отпускаются по рецептам врачей с 50-процентной скидкой, сформированным в объеме не менее утвержденного распоряжением Правительства Российской Федерации на соответствующий год перечня жизненно необходимых и важнейших лекарственных препаратов, за исключением лекарственных препаратов, используемых исключительно в стационарных условиях...» [5].

На основании Ф3 «Об основах охраны здоровья» и ПГГ к полномочиям субъектов РФ относятся формирование вышеуказанного перечня лекарственных препаратов и финансирование обеспечения лекарственными препаратами региональных льготников [1,5].

В территориальных программах государственных гарантий бесплатного оказания гражданам медицинской помощи (далее территориальные ПГГ) перечни лекарственных препаратов для региональных льготников являются приложением к самой программе.

Категории граждан, относящиеся к региональным льготникам в настоящее время определяются постановлением Правительства РФ от 30.07.1994 №890 «О государственной поддержке развития медицинской промышленности и улучшении обеспечения населения и учреждений здравоохранения лекарственными средствами и изделиями медицинского назначения» (далее - Постановление 890), которое было утверждено в 1994 году и последний раз редактировалось в 2002 году. Основная цель данного нормативного документа - развитие фармацевтической промышленности в РФ в целях улучшения обеспечения населения лекарственными средствами и изделиями медицинского назначения, в том числе 
учреждений здравоохранения. В связи с повсеместным введением системы ОМС с 1994 года обеспечение лекарственными препаратами в медицинских организациях, оказывающих медицинскую помощь в стационарных условиях, финансируется из средств ОМС, что делает Постановление 890 неактуальным в этой части.

Кроме того, Постановление 890 также содержит нормы, относящиеся к поддержке аптечных организаций, и другие аспекты, которые не соответствуют сложившейся на сегодняшний день действительности, в том числе по распределению финансовых потоков и полномочий:

«5. Рекомендовать органам государственной власти субъектов Российской Федерации за счет средств соответствующих бюджетов и иных источников:

понижать для производств, выпускающих лекарственные средства и изделия медицинского назначения, тарифы на услуги водоснабжения и водоотведения (в ред. Постановления Правительства РФ от 27.12.1997 №1629); ...

...осуществлять финансовую поддержку предприятий аптечной сети, испытывающих недостаток в оборотных средствах...»).

В 1994 году не существовало разделения полномочий по части лекарственного обеспечения населения. Также очень важно отметить, что на федеральном уровне Постановлением 890 для субъектов РФ утвержден «Перечень групп населения и категорий заболеваний, при амбулаторном лечении которых лекарственные средства и изделия медицинского назначения отпускаются по рецептам врачей бесплатно» (Приложение №1), и «Перечень групп населения, при амбулаторном лечении которых лекарственные средства отпускаются по рецептам врачей с 50-процентной скидкой» (Приложение №2). Кроме того, в приложении №1 к Постановлению 890 в виде таблицы представлены группы населения и перечень лекарственных средств и изделий медицинского назначения, отпускаемых по рецептам врачей бесплатно [6].
В тоже время, в территориальных программах государственных гарантий (далее территориальные ПГГ) бесплатного оказания гражданам медицинской помощи данные перечни лекарственных препаратов для региональных льготников являются приложением к территориальной ПГГ [6].

Следовательно, Ф3 «Об основах охраны здоровья» и постановлением Правительства РФ полномочия по формированию вышеуказанного перечня лекарственных препаратов и финансированию обеспечения лекарственными препаратами в соответствии с данным перечнем отнесены к полномочиям субъектов РФ.

На региональном уровне при осуществлении лекарственного обеспечения льготных категорий граждан возникают следующие актуальные практические вопросы, требующие разрешения на законодательном уровне:

1. Следует ли субъектам РФ руководствоваться вышеуказанным Постановлением Правительства РФ №890 от 1994 года и иметь в региональных льготниках только те категории граждан и группы заболеваний, и, соответственно, только те лекарственные препараты, которые указаны в постановлении Правительства РФ?

2. При признании Постановления №890 обязательным для исполнения, что считать под обеспечением «всеми лекарственными средствами»?

3. Могут ли субъекты РФ, реализуя свои полномочия за счет собственных региональных бюджетов, формировать собственные перечни региональных льготников и лекарственных препаратов для их обеспечения?

Основные законодательные вопросы лекарственного обеспечения региональных льготников

Что касается первого вопроса, ряд экспертов признает формирование перечня закупаемых из региональных бюджетов лекарственных препаратов и региональных льготников полномочием субъектов РФ на основании норм части 1 статьи 16 и п. 5) ч. 2 статьи 81 Ф3 «Об основах охраны здоровья». С учетом статьи 73 Конституции 
РФ, которая устанавливает, что «вне пределов ведения Российской Федерации и полномочий Российской Федерации по предметам совместного ведения Российской Федерации и субъектов Российской Федерации субъекты Российской Федерации обладают всей полнотой государственной власти», субъекты РФ должны самостоятельно реализовывать полномочия по предметам ведения субъектов РФ [7].

Однако существует мнение ряда экспертов, что регионы должны формировать Перечни на основании Постановления №890 - действующего федерального нормативного правового акта. При согласии с данной точкой зрения возникает еще несколько вопросов.

Перечень изделий медицинского назначения и лекарственных средств, которые отпускаются по рецептам врачей бесплатно и перечислены в графе 2 таблицы в Приложении №1 Постановления 890 состоит из определений: «лекарственные средства для лечения данной категории заболеваний»; «в соответствии с перечнем жизненно необходимых и важнейших лекарственных средств»; «все лекарственные средства, а при отдельных категориях заболеваний указаны перечни групп лекарственных препаратов.

Для ряда льготников, страдающих следующими категориями заболеваний: СПИД, ВИЧ-инфицированные; онкологические заболевания; лепра; диабет; психические заболевания (инвалиды I и II групп, а также больные, работающие в лечебнопроизводственных государственных предприятиях для проведения трудовой терапии, обучения новым профессиям и трудоустройства на этих предприятиях, шизофрения и эпилепсия), а также почти все льготные категории граждан по определению «группы населения» (39 групп населения, включая детей первых трех лет жизни, а также детей из многодетных семей в возрасте до 6 лет, инвалидов I группы, неработающих инвалидов II группы, детей-инвалидов в возрасте до 18 лет), предусмотрено обеспечение «всеми лекарственными препаратами». Если дословно проанализи- ровать указанную формулировку, можно предположить, что имеется в виду обеспечение всеми лекарственными препаратами, зарегистрированными на территории РФ. К примеру, в соответствии с Постановлением 890 дети из многодетных семей в возрасте до шести лет и дети первых трех лет жизни имеют право на выписку врачами бесплатного рецепта на все лекарственные препараты.

Следовательно, не должно существовать никакого регионального перечня лекарственных препаратов для данных категорий граждан, поскольку любой региональный перечень будет ограничительным из-за того, что не включает в себя все зарегистрированные в РФ лекарственные препараты, что повлечет за собой нарушение прав граждан и будет предметом юридических споров. При этом следует отметить, что перечень из всех зарегистрированных в нашей стране лекарственных препаратов также может быть расценен как нарушение прав льготных категорий граждан, поскольку существуют законодательные нормы, регулирующие в ряде случаев использование незарегистрированных в РФ лекарственных препаратов (Федеральный закон от 12.04.2010 №61-Ф3 «Об обращении лекарственных средств», Федеральный закон от 21.11.2011 №323-Ф3 «Об основах охраны здоровья граждан в Российской Федерации», Постановление Правительства РФ от 29 сентября 2010 г. №771 «О порядке ввоза лекарственных средств для медицинского применения на территорию Российской Федерации», Федеральный закон от 05.04.2013 №44-Ф3 «О контрактной системе в сфере закупок товаров, работ, услуг для обеспечения государственных и муниципальных нужд», Приказ Министерства здравоохранения РФ от 2 августа 2012 г. №58н «Об утверждении Административного регламента Министерства здравоохранения Российской Федерации по предоставлению государственной услуги по выдаче разрешений на ввоз на территорию Российской Федерации конкретной партии зарегистрированных и (или) незарегистрированных лекарствен- 
ных средств, предназначенных для проведения клинических исследований лекарственных препаратов, конкретной партии незарегистрированных лекарственных средств, предназначенных для проведения экспертизы лекарственных средств в целях осуществления государственной регистрации лекарственных препаратов, конкретной партии незарегистрированных лекарственных средств для оказания медицинской помощи по жизненным показаниям конкретного пациента») [8].

Таким образом, если Постановление 890 обязательно к исполнению, то необходимо наличие списка лекарственных препаратов для лекарственного обеспечения региональных льготников.

Основные практические вопросы лекарственного обеспечения региональных льготников

На практике к рассмотренным выше законодательным вопросам лекарственного обеспечения региональных льготников добавляются сложности, связанные с ограниченностью регионального бюджета. Очевидно, что при отсутствии какого-либо списка лекарственных препаратов, потребность в обеспечении всеми зарегистрированными (в Российской Федерации и в мире) лекарственными препаратами ни один региональный бюджет покрыть не сможет. Таким образом, если субъекты РФ будут строго придерживаться Постановления 890, то у них не хватит средств бюджета на реализацию установленных полномочий.

Однако, существуют риски признания Постановления 890 необязательным к исполнению. Факт признания Постановления Правительства РФ необязательным к исполнению грозит санкциями для субъекта РФ. При этом, если субъекты РФ будут создавать только собственные категории заболеваний и группы региональных льготников в условиях дефицитных бюджетов, существует риск, что данные льготные категории будут сведены к минимуму.

Также существует проблема с формированием списков лекарственных препаратов для лекарственного обеспечения отдельных категорий граждан на региональ- ном уровне. Отсутствие утвержденной регламентации данной процедуры приводит к тому, что региональные перечни лекарственных препаратов отличаются в различных субъектах РФ по количеству представленных международных непатентованных наименований (МНH). Так, например, на 2017 год в Санкт-Петербурге региональный перечень содержал $340 \mathrm{MHH}$, а в Тюменской области - $660 \mathrm{MHH} \mathrm{[8].}$

Указанная ситуация, как отмечают эксперты, не связана с различиями в структуре заболеваемости, половозрастной структуре населения в регионе, а обусловлена именно отсутствием единых требований к формированию региональных перечней лекарственных препаратов в регионах РФ и разным уровнем благосостояния региона [9]. Единым для регионов является то, что с 2019 года ПГГ устанавливает объем данных перечней в размере не менее ЖНВЛП [5].

Очень важно отметить и то, что при формировании региональных перечней лекарственных препаратов в большинстве случаев не учитываются клинико-экономические (фармако-экономические) характеристики препаратов, в результате чего выбор терапии в таком случае будет осуществляться без учета определения наиболее предпочтительного соотношения затрат и эффективности различных лекарственных препаратов. Также не принимается во внимание анализ влияния на бюджет использования различных схем лечения, что приводит к нерациональному расходованию ограниченных средств субъектов РФ [10].

Также следует обратить внимание на тот факт, что нормативные правовые акты федерального уровня содержат указание, что региональный перечень лекарственных препаратов должен содержать препараты для оказания медицинской помощи «в амбулаторных условиях». Амбулаторные условия предполагают назначение врачом лекарственного препарата и прием последнего самостоятельно или введение препарата в условиях процедурного кабинета поликлиники, без непосредственного контроля со стороны врача во время приема или введения. Указанное применение 
лекарственных препаратов возможно, в первую очередь, для таблетированных препаратов и для ряда препаратов, вводимых подкожно. Напротив, невозможно применение в данных условиях внутривенным капельным способом или введение лекарственных препаратов, когда необходим непосредственный контроль врача.

Приказ Минздрава РФ от 14 января 2019 года №4н «Об утверждении порядка назначения лекарственных препаратов, форм рецептурных бланков на лекарственные препараты, порядка оформления указанных бланков, их учета и хранения» пунктом 8 запрещает выписывать медицинским работникам рецепт на лекарственные препараты, которые в соответствии с инструкцией по медицинскому применению используются только в медицинских организациях. Следовательно, региональный перечень лекарственных препаратов не может содержать препараты, которые в соответствии с инструкцией вводятся пациенту только в медицинской организации (при оказании медицинской помощи в условиях дневного стационара или стационара).

Нормативно-правовые акты, регулирующие лекарственное обеспечение незарегистрированными в Российской Федерации лекарственными препаратами

Еще одним актуальным вопросом лекарственного обеспечения является во3можность использования лекарственных препаратов, незарегистрированных в Российской Федерации.

На основании существующей законодательной базы, статья 29 Федерального закона №323-Ф3 «Об основах охраны здоровья граждан в Российской Федерации» регламентирует организацию охраны здоровья, которая обеспечивается, в том числе путем обеспечения определенных категорий граждан Российской Федерации лекарственными препаратами в соответствии с законодательством Российской Федерации. А в законодательстве РФ предусмотрена возможность обеспечения граждан не только зарегистрированными, но и не зарегистрированными на территории РФ лекарственными препаратами.
Обеспечение пациентов необходимыми лекарственными средствами, не зарегистрированными на территории Российской Федерации, регламентируется Федеральным законом от 21.11.2011 №323Ф3 «Об основах охраны здоровья граждан в Российской Федерации», Федеральным законом от 12.04.2010 №61-Ф3 «Об обращении лекарственных средств», Федеральным законом от 05.04.2013 №44-Ф3 «О контрактной системе в сфере закупок товаров, работ, услуг для обеспечения государственных и муниципальных нужд», Постановлением Правительства РФ от 29 сентября 2010 года №771 «О порядке ввоза лекарственных средств для медицинского применения на территорию Российской Федерации», Приказом Министерства здравоохранения РФ от 2 августа 2012 года №58н «Об утверждении Административного регламента Министерства здравоохранения Российской Федерации по предоставлению государственной услуги по выдаче разрешений на ввоз на территорию Российской Федерации конкретной партии зарегистрированных и (или) незарегистрированных лекарственных средств, предназначенных для проведения клинических исследований лекарственных препаратов, конкретной партии незарегистрированных лекарственных средств, предназначенных для проведения экспертизы лекарственных средств в целях осуществления государственной регистрации лекарственных препаратов, конкретной партии незарегистрированных лекарственных средств для оказания медицинской помощи по жизненным показаниям конкретного пациента».

Согласно статьи 47 Федерального закона от 12.04.2010 №61-Ф3 «Об обращении лекарственных средств» допускается ввоз на территорию нашей страны конкретной партии незарегистрированных лекарственных средств, предназначенных для оказания медицинской помощи по жизненным показаниям конкретного пациента на основании разрешения, выданного уполномоченным федеральным органом исполнительной власти [11]. 


\section{Заключение}

Представленный анализ законодательной базы указал нормативно-правовые акты, регламентирующее лекарственное обеспечение льготных категорий граждан на федеральном и региональном уровнях. Выявлено, что с одной стороны, существует система по распределению бюджетных средств в соответствии с установленными категориями граждан и действующими ограничительными перечнями лекарственных препаратов, с другой стороны - имеются не до конца разрешенные противоречия и дублирования в законодательных актах, что негативно сказывается на организации здравоохранения в нашей стране.

Однако, нормативная база изменяется, обновляясь с утверждением новых программ государственных гарантий, федеральных перечней лекарственных препаратов и прочих нормативных документов. Таким образом, имеются дальнейшие перспективы по обновлению законодательных актов, которые были утверждены достаточно давно и требуют гармонизации с действующей на сегодняшней день нормативно-правовой базой.

На региональном уровне существуют до конца нерешенные законодательные и практические трудности. Для их решения необходима доработка существующих нормативно-правовых актов или разработка новой законодательной базы. При этом оба пути представляют собой сложную задачу, от решения которой зависят жизнь и здоровье отечественных пациентов.

\section{Литература}

1. Федеральный Закон от 21.11.2011 №323 «Об основах охраны здоровья граждан в Российской Федерации» (в ред. от 06.03.2019). Доступно по: https://base.garant.ru/57499516/. Ссылка активна на 07 июня 2019.

2. Федеральный закон от 17.07.99 №178 «О государственной социальной помощи». Доступно по: http://www.consultant.ru/document/cons_doc_ LAW_23735/. Ссылка активна на 07 июня 2019.

3. Распоряжение Правительства РФ от 10.12.2018 №2738-p «Об утверждении перечня жизненно необходимых и важнейших лекарственных препаратов на 2019 год, а также перечней лекарственных препаратов для медицинского применения и минимального ассортимента лекарственных препаратов, необходимых для оказания медицинской помощи». Доступно по: http://www.consultant.ru/document/cons_doc_LA W_313085/. Ссылка активна на 26 июня 2019.

4. Приказ МЗ СР РФ от 9 марта 2007 года №159 «О мерах по обеспечению отдельных категорий граждан необходимыми лекарственными средствами». Доступно по: http://www.consultant.ru/ cons/cgi/online.cgi?req=doc\&base $=E X P \& n=3961$ 49\#02998711554305644. Ссылка активна на 26 июня 2019.

5. Программа государственных гарантий бесплатного оказания гражданам медицинской помощи 2019 (утв. Постановлением Правительства РФ от 10 декабря 2018 года №1506). Доступно по: https://sudact.ru/law/postanovlenie-pravitelstva-rfot-10122018-n-1506/programma-gosudarstvennykh -garantii-besplatnogo-okazaniia/. Ссылка активна на 26 июня 2019.
6. Постановление Правительства РФ от 30.07.1994 №890 «О государственной поддержке развития медицинской промышленности и улучшении обеспечения населения и учреждений здравоохранения лекарственными средствами и изделиями медицинского назначения». Доступно по: https://base.garant. ru/101268/. Ссылка активна на 26 июня 2019.

7. Конституция Российской Федерации (с учетом поправок, внесенных Законами Российской Федерации о поправках к Конституции Российской Федерации от 30.12.2008 N 6-ФКЗ, от 30.12.2008 N 7-ФКЗ, от 05.02.2014 N 2-ФКЗ, от 21.07.2014 N 11-ФКЗ). Доступна по: http://www.consultant.ru/document/cons_doc_LAW_28399/. Ссылка активна на 26 июня 2019.

8. Маличенко В.С., Маличенко С.Б., Явися А.М. Особенности организации амбулаторного лекарственного обеспечения отдельных групп населения в Российской Федерации // Медикосоциальная экспертиза и реабилитация. 2016. Т. 19, №2. С. 103-108. doi:10.18821/1560-95372016-19-2-103-108

9. Александрова О.Ю., Нагибин О.А. Перечень жизненно необходимых и важнейших лекарственных препаратов - значение понятий для конкретизации госгарантий бесплатности лекарственной медицинской помощи // Менеджер здравоохранения. 2015. №4. С. 25-32.

10. Александрова О.Ю., Нагибин О.А. Стандарты медицинской помощи - значение понятия для конкретизации государственных гарантий бесплатности лекарственной медицинской помощи // Менеджер здравоохранения. 2015. №3. С. 6-15.

11. Федеральный закон от 12.04.2010 №61-Ф3 «Об обращении лекарственных средств». Доступно 
по: https://base.garant.ru/12174909/. Ссылка активна на 07 июня 2019.

\section{References}

1. Federal Law №323 of 21 November 2011 « Ob osnovakh okhrany zdorov'ya grazhdan v Rossiyskoy Federatsii» (ed. at 06.03.2019). Available at: https://base.garant.ru/57499516/. Accessed: 2019 June 07. (In Russ).

2. Federal Law №178 of 17 July 1999 «O gosudarstvennoy sotsial'noy pomoshchi». Available at: http:// www.consultant.ru/document/cons_doc_LAW_23 735/. Accessed: 2019 June 07. (In Russ).

3. Order of the Government of the Russian Federation at 20 December 2018 №2738-r «Ob utverzhdenii perechnya zhiznenno neobkhodimykh i vazhneyshikh lekarstvennykh preparatov na 2019 god, a takzhe perechney lekarstvennykh preparatov dlya meditsinskogo primeneniya i minimal'nogo assortimenta lekarstvennykh preparatov, neobkhodimykh dlya okazaniya meditsinskoy pomoshchi». Available at: http://www.consultant.ru/document/cons_doc LAW_313085/. Accessed: 2019 June 26. (In Russ).

4. Order of the Ministry of Health and Social Development at 9 March 2007 №159 «O merakh po obespecheniyu otdel'nykh kategoriy grazhdan neobkhodimymi lekarstvennymi sredstvami». Available at: http://www.consultant.ru/cons/cgi/ online. cgi?req=doc\&base $=$ EXP\&n $=396149 \# 0299871155$ 4305644. Accessed: 2019 June 26. (In Russ).

5. Programma gosudarstvennykh garantiy besplatnogo okazaniya grazhdanam meditsinskoy pomoshchi 2019 (ed. Order of the Government RF at 10 December 2018 №1506). Available at: https://sudact.ru/law/postanovlenie-pravitelstva-rfot-10122018-n-1506/programma-gosudarstvennykh-garantii-besplatnogo-okazaniia/. Accessed:
2019 June 26. (In Russ).

6. Government Decree of the Russian Federation at 30 Jule 1994 №890 «O gosudarstvennoj podderzhke razvitiya medicinskoj promy`shlennosti i uluchshenii obespecheniya naseleniya i uchrezhdenij zdravooxraneniya lekarstvenny`mi sredstvami i izdeliyami medicinskogo naznacheniya». Available at: https://base.garant.ru/101268/. Accessed: 2019 June 26. (In Russ).

7. Constitution of the Russian Federation (subject to amendments made by the Laws of the Russian Federation on amendments to the Constitution of the Russian Federation №6-FCL at 30.12.2008, №7FCL at 30.12.2008, №2-FCL at 05.02.2014, №11FCL at 21.07.2014). Available at: http://www.consultant.ru/ document/cons_doc_LAW_28399/. Accessed: 2019 June 26. (In Russ).

8. Malichenko VS, Malichenko SB, Yavisya AM. Features of the organization of outpatient drug supply for certain population groups in the Russian Federation. Medical and Social Expert Evaluation and Rehabilitation. 2016;19(2):103-8. (In Russ). doi:10.18821/1560-9537-2016-19-2-103-108

9. Aleksandrova OU, Nagibin OA. List of vital and life critical drugs; meanings of the definition for specifying state guarantees for free drug medical aid. Menedzher Zdravoohranenija. 2015;(4):25-32. (In Russ).

10. Aleksandrova OU, Nagibin OA. Standards of medical aid - meaning of the definition for specifying state guarantees of free drug medical aid. Menedzher Zdravoohranenija. 2015;(3):6-15. (In Russ).

11. Federal Law at 12 April 2010 №61-FL «Ob obrashchenii lekarstvennykh sredstv». Available at: https://base.garant.ru/12174909/. Accessed: 2019 June 07. (In Russ).

Информация об авторах [Authors Info]

*Нагибин Олег Александрович - к.м.н., доцент кафедры общественного здоровья и здравоохранения с курсом организации здравоохранения ФДПО, Рязанский государственный медицинский университет имени академика И.П. Павлова, Рязань, Российская Федерация. E-mail: oanagibin@yandex.ru

SPIN: 2124-7580, ORCID ID: 0000-0003-3154-6754.

Oleg A. Nagibin - MD, PhD, Associate Professor of the Department of Social Health and Healthcare with a Course of Healthcare Organization at Faculty of Additional Professional Education, Ryazan State Medical University, Ryazan, Russian Federation. E-mail: oanagibin @yandex.ru SPIN: 2124-7580, ORCID ID: 0000-0003-3154-6754.

Селявина Ольга Николаевна - ассистент кафедры экономики, права и управления здравоохранением, Рязанский государственный медицинский университет имени академика И.П. Павлова, Рязань, Российская Федерация.

SPIN: 8720-2880, ORCID ID: 0000-0001-7198-9176.

Olga N. Selyavina - Assistant of the Department of Economics, Law and Health Management, Ryazan State Medical University, Ryazan, Russian Federation.

SPIN: 8720-2880, ORCID ID: 0000-0001-7198-9176.

Караущева Людмила Евгеньевна - к.м.н., доцент кафедры экономики, права и управления здравоохранением, Рязанский государственный медицинский университет имени академика И.П. Павлова, Рязань, Российская Федерация.

SPIN: 3465-1271, ORCID ID: 0000-0003-3910-3130.

Liudmila E. Karausheva - MD, PhD, Associate Professor of the Department of Economics, Law and Health Management, Ryazan State Medical University, Ryazan, Russian Federation.

SPIN: 3465-1271, ORCID ID: 0000-0003-3910-3130. 
Цитировать: Нагибин О.А., Селявина О.Н., Караушева Л.Е. Анализ нормативно-правовых актов по организации лекарственного обеспечения отдельных категорий граждан, имеющих право на меры социальной поддержки // Наука молодых (Eruditio Juvenium). 2020. T. 8, №2. C. 284-295. doi:10.23888/HMJ202082284-295

To cite this article: Nagibin OA, Selyavina ON, Karausheva LE. Analysis of regulatory legal acts on organization of pharmaceutical provision of certain categories of citizens with the right to social support. Science of the young (Eruditio Juvenium). 2020;8(2):284-95. doi:10.23888/ HMJ202082284-295

Поступила / Received: 04.11.2019

Принята в печать / Accepted: 02.06.2020 